\title{
Treatment of Biliary Atresia by Portoenterostomy and Liver Transplantation: The Queen Mary Hospital, Hong Kong Experience
}

\author{
Htut Saing, Sheung Tat Fan, Kwong Leung Chan, \\ William Wei, George Hlaing Mya, Chung Mau Lo and \\ Wei Cheng \\ Department of Surgery, The University of Hong Kong, \\ Queen Mary Hospital, Hong Kong
}

Saing, H., Fan, S.T., Chan, K.L., Wei, W., Mya, G.H., Lo, C.M. and Cheng, W. Treatment of Biliary Atresia by Portoenterostomy and Liver Transplantation: The Queen Mary Hospital, Hong Kong Experience. Tohoku J. Exp. Med., 1997, 181 (1), 109-116 - Ninety three out of 96 patients with biliary atresia (BA) underwent Kasai 1 portoenterostomy and 11 children subsequently underwent 12 liver transplantation (LTX) procedures which included 8 living related liver transplants (LRLT), 3 reduced-size liver transplants (RSLT) and 1 orthotopic liver transplantation (OLT). During a follow-up period of $3-206$ months (mean, 73 months) after portoenterostomy and 3-63 months after LTX, $50 \%$ of 96 patients are alive and well with total clearance of jaundice while $12 \%$ are mildly jaundiced, $10 \%$ are deeply jaundiced and $28 \%$ have died. Two of the 3 patients who did not undergo portoenterostomy and 25 from the portoenterostomy group have died. Of the latter group, 22 deaths occurred before, and 3 after the introduction of LTX therapy respectively. Of the 68 long-term survivors, 32 are less than 5, and 36 are 6-17 years old. Complete clearance of jaundice was achieved in $55 \%$ of patients irrespective of whether portoenterostomy was initially performed at $<10$ or between 10 and 12 weeks. Portoenterostomy performed beyond 13 weeks was associated with declining results. We conclude that (1) portoenterostomy combined with liver transplantation, when indicated, has given patients with BA a much better prognosis and (2) pediatric LTX in our institute is a well established procedure with $100 \%$ patient and $88 \%$ primary graft survival._— biliary atresia; portoenterostomy; liver transplantation; microvascular surgery

As the sole pediatric surgery center established some 15 years ahead of any other centers in Hong Kong, the largest number of patients with biliary atresia (BA) are seen and managed by us. Since 1993, we have introduced pediatric liver

Received June 30, 1996; revision accepted for publication November 15, 1996.

Address for reprints: Professor Htut Saing, Chief, Division of Paediatric Surgery, Department of Surgery, The University of Hong Kong, Queen Mary Hospital, Hong Kong.

This paper was presented at 6th International Sendai Symposium on Biliary Atresia, May 20 and 21, 1996, Seniai. 
transplantation as a complementary procedure to portoenterostomy, having previously sent 3 children for liver transplantation overseas. We report herein our experience in managing 96 patients with BA since 1979.

\section{Methods}

\section{Patients}

This is a retrospective study of 96 patients who suffered from non-correctable form of biliary atresia managed by the Division of Pediatric Surgery, Department of Surgery, The University of Hong Kong, Queen Mary Hospital between May 1979 and December 1995. The cohort of patients included those operated on by us as well as those referred to us following exploration and/or operation by others. The age at initial portoenterostomy/exploration ranged from $<1$ to 8 months (mean, 2 months). Of the 96 patients, 93 underwent portoenterostomy and 3 did not; 10 of the former group and 1 from the latter group eventually underwent liver transplantation. Except for the 3 patients who did not have initial portoenterostomy, the rest have undergone 1 to 3 previous abdominal operations. The follow-up period was 3-206 months (mean, 73 months).

\section{Portoenterostomy}

We have consistently utilized only the original Kasai 1 procedure using a 40-cm Roux-loop. Despite the introduction of various modifications to reduce postoperative cholangitis, we have resisted adopting any of the modifications including cutaneous stomas, antireflux procedures, and various forms of gastrointestinal conduits for biliary drainage.

We have strictly adhered to the following levels of bilirubin in classifying our patients: well = bilirubin level $\leq 24 \mu \mathrm{mol} /$ liter, mild jaundice $=$ bilirubin levels between $\geq 25$ and $100 \mu \mathrm{mol} /$ liter and bilirubin level above $100 \mu \mathrm{mol} /$ liter is considered deep jaundice.

\section{Liver transplantation}

Between 1990 and 1993, 3 children with end-stage liver disease were subjected to liver transplantation overseas. One child underwent a living-related liver transplant (LRLT), 1 a reduced-size liver transplant (RSLT) and an older child underwent an orthotopic liver transplant (OLT). From September 1993 onward, 8 children underwent 9 transplant procedures in our institution, these being 7 LRLT and 2 RSLT. The retransplant (LRLT) was performed for a child 18 months after the initial RSLT which functioned well at the beginning but subsequently the child developed chronic hepatitis of undetermined etiology.

The status of the children undergoing LTX was classified according to the

new United Network for Organ Sharing (UNOS) classification. One child belonged to UNOS status 1 (in ICU on ventilator for shock following massive gastrointestinal bleeding), 8 patients were in UNOS status 2 (hospitalized for treatment 
of complications arising from end-stage liver disease), and 3 were in UNOS status 3 (requiring frequent admission for the management of sequelae of liver failure). There were no patients belonging to UNOS 4.

Hepatic artery anastomosis was performed by a completely fresh team of surgeons experienced in microvascular techniques using an operating microscope under $6 \mathrm{x}-9 \mathrm{x}$ magnification and $9-0$ prolene sutures.

\section{Results}

During a follow-up period ranging from 3 to 206 months (mean, 73 months) for portenterostomy and 3 to 63 months for liver transplantation (LTX), $50 \%$ of the 96 patients are alive and well with total clearance of jaundice while $12 \%$ are mildly jaundiced, $10 \%$ are in deep jaundice and $28 \%$ have died. Three out of 25 deaths occurred since the introduction of LTX and were due to non-availability of cadaveric livers for transplantation and also because the potential living donors were considered unsuitable or were unavailable to donate the liver segments.

The age distribution of the survivors following portoenterostomy and LTX when indicated is shown in Fig. 1. Thirty six $(53 \%)$ of the survivors are more than 5 years of age and $15(22 \%)$ are above 10 years of age. One point of interest in our series is that with our treatment protocol of combining portoenterostomy with LTX when necessary, we obtained total clearance of jaundice in $55 \%$ of our patients irrespective of whether we performed portoenterostomy at age less than 10 weeks or between 10 and 12 weeks (Fig. 2). It is also worthy of note that in 9 patients operated upon beyond 15 weeks of age, we were able to obtain clearance of jaundice in one-third of our patients.

The results of liver transplantation have been most encouraging. All 11 patients who underwent 12 LTXs are alive and well, free from jaundice and are enjoying an excellent quality of life. The outcome of management of our patients is shown in Fig. 3.

Surgical complications in the recipients of LTX group included bleeding in 2 patients, one from the right hepatic vein stump and the other from drain site and both children required re-exploration. One child required resection and anas-

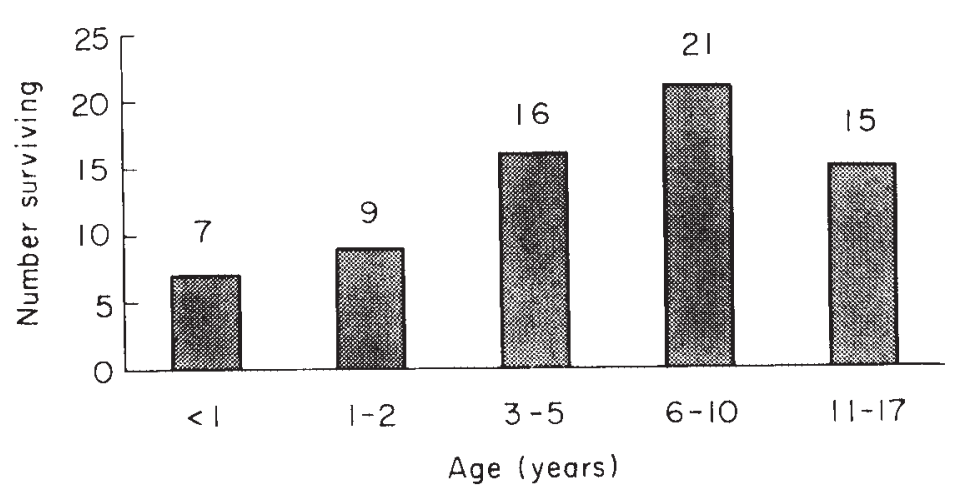

Fig. 1. Age distribution of survivors. $n=68$. 


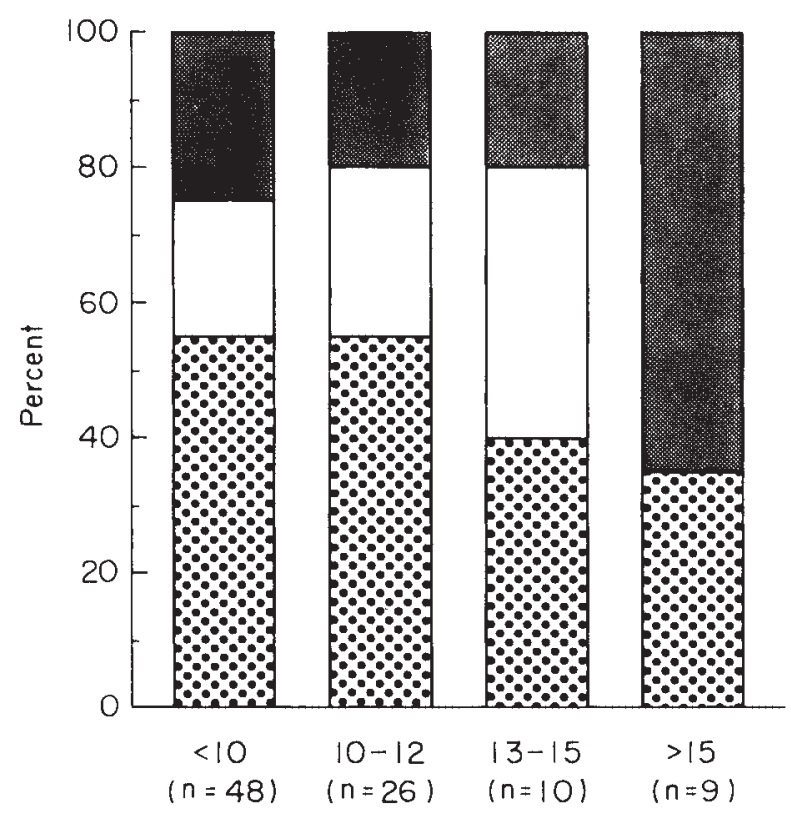

Age at operation (weeks)

Fig. 2. Age at operation and long-term results of biliary atresia.

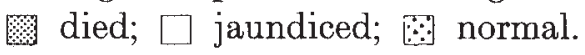

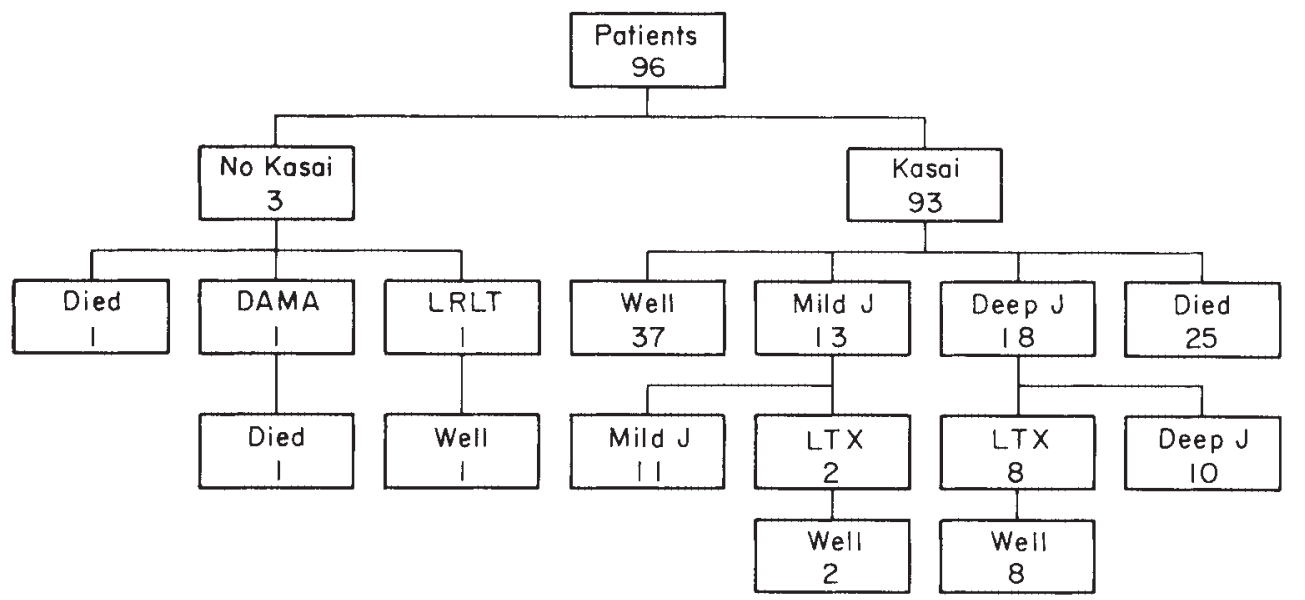

Fig. 3. Outcome of management of biliary atresia by portoenterostomy and/or liver transplantation.

Kasai $=$ Kasai 1 operation. DAMA $=$ Discharged against medical advice. LTX $=$ Liver transplant. Well $=$ Normal level of bilirubin $(<24 \mu \mathrm{mol} / \mathrm{liter})$. Mild $J=$ Mild jaundice (bilirubin $24-100 \mu \mathrm{mol} /$ liter). Deep $J=$ Deep jaundice (bilirubin $>100 \mu \mathrm{mol} /$ liter).

tomosis of a part of transverse colon due to major breach and injury during dissection of dense adhesions. Prolonged massive ascites occurred in one child requiring repeated paracentesis while another developed skin necrosis on the dorsum of hand which was treated with wound debridement and skin graft.

Graft complications included kink and fibrosis of hepatic vein in 1 patient and stenosis of the biliary-enteric anastomosis in 2 patients. All these 3 complications were successfully managed by single sessions of percutaneous transjugular or 
transhepatic balloon dilatation, respectively. There was no hepatic artery thrombosis (HAT) nor portal vein thrombosis in our series.

All donors are alive and well and are pursuing activities which they indulged in before donation. They were discharged 4-7 days postoperatively (mean, 6 days).

Looking at the results of portoenterostomy alone, out of 93 patients who underwent portoenterostomy, $37(40 \%)$ are alive and well with total clearance of jaundice, $13(14 \%)$ were mildly jaundiced, $18(19 \%)$ were in deep jaundice and 25 (27\%) have died (Fig. 3). Out of 3 patients who did not undergo portnoeterostomy, 2 have died and $l$ is alive and well having undergone LTX procedure.

\section{Discussion}

The major breakthrough in the management of "non-correctable" type of biliary atresia was by Kasai and Suzuki (1959) when they introduced hepatic portoenterostomy. Since then, the results of surgery have greatly improved and recent reports show that disappearance of jaundice ranged from $39 \%$ to $76 \%$ (Schweizer 1986; Caccia et al. 1987; Canty 1987; Chen 1987; Kim et al. 1987; Saing and Tam 1987; Vacanti et al. 1990). This wide variation may be due to the fact that in some reports, the authors have not clearly indicated whether the results were for early or late follow-up cases (Ohi and Ibrahim 1992). Our jaundice clearance rate of $40 \%$ for patients who underwent portoenterostomy alone over a mean follow-up period of 73 months compares favourably with other investigators.

In the current literature, biliary atresia is associated with 5-year survival rates of $30 \%$ to $75 \%$ (Lilly 1986; Houwen et al. 1989; Hall and Karrer 1990; Karrer et al. 1990; Knisely 1990; Stewart et al. 1990). However, the application of pediatric liver transplantation to patients with failed portoenterostomy or in those who have developed end-stage liver disease after initially having moderate to good bile drainage, has given these patients an additional gift of life (Superina et al. 1990; Vacanti et al. 1990; Ryckman et al. 1993; Broelsch et al. 1994; Otte et al. 1994).

During the follow-up period, $50 \%$ of the 96 patients, including 11 who have undergone LTX are alive and well, totally free from jaundice. However, our jaundice free patients would have been only $40 \%$ if we had applied portoenterostomy alone. Our liver transplant program for children started in September 1993. From May 1979 to September 1993, 22 children who received portoenterostomy and 2 other patients who did not receive portoenterostomy died. Three more children who have undergone portoenterostomy have died since the start of our pediatric liver transplant program. If not for the LTXs on 8 children which we performed in our institution and the $3 \mathrm{LTXs}$ performed overseas, our overall mortality would have been increased from 27 out of $96(28 \%)$ to 38 out of 96 $(40 \%)$. These numbers are indicative of the favorable outcome of portoenteros- 
tomy which is complemented by LTX whenever indicated. We concur fully with other investigators that portoenterostomy should be offered to patients with biliary atresia in the first instance and be complemented by LTX once indications for transplantation become apparent (Vacanti et al. 1990; Ryckman et al. 1993; Otte et al. 1994).

In Hong Kong, although the concept of brain death is accepted due to legislation, the traditional belief that no part of the body be removed after death has greatly hindered organ procurement. For this reason, we have had to develop LRLT although our initial efforts were aimed at performing RSLT. The techniques (Tanaka et al. 1993) as well as the superior results obtained from LRLT have been well documented (Heffron 1993; Broelsch et al. 1994) and these have greatly encouraged us to proceed with the development with the LRLT program.

The dreaded complication of LTX is hepatic artery thrombosis (HAT) and its incidence varies between $6 \%$ and $38 \%$ (Tzakis et al. 1985; Shaw et al. 1988; Tan et al. 1988; Otte et al. 1990; Busuttil et al. 1991). HAT constitutes the single most common serious complication after pediatric LTX and is associated with a very high mortality rate of approximately $50 \%$ (Tzakis et al. 1985). We are impressed with the absence of HAT when hepatic artery anastomosis was performed using microvascular techniques (Mori et al. 1992; Tanaka et al. 1993). We therefore adopted this technique from the very first case of pediatric LTX whereby a totally fresh team of surgeons experienced in microvascular techniques performed the hepatic artery anastomosis using microvascular techniques. So far, we have not had HAT in our series of LTX and despite the lack of controlled trials, we are convinced that microvascular techniques have a major role to play in reducing the incidence of HAT.

\section{References}

1) Broelsch, C.E., Burdelski, M., Rogiers, X. \& Gundlach, M. (1994) Living donor for liver transplantation. Hepatology, 20, 49S-55S.

2) Busuttil, R.W., Seu, P., Millis, J.M., Olthoff, K.M., Hiatt, J.R., Milewicz, A., Nuesse, B., El-Khoury, G., Raybould, D., Nyerges, A., Vargas, J., McDiarmid, S., Berquist, W., Harrison, R. \& Ament, M. (1991) Liver transplantation in children. Ann. Surg., 213, 48-57.

3) Caccia, G., Dessanti, A. \& Alberti, D. (1987) Clinical results in 90 patients with biliary atresia. In: Biliary Atresia, edited by R. Ohi, Professional Postgraduate Services, Tokyo, pp. 281-286.

4) Canty, T.G. (1987) Encouraging results with a modified Sawaguchi hepatoportoenterostomy for biliary atresia. Am. J. Surg., 154, 19-26.

5) Chen, W. J. (1987) Recent results of surgical treatment for biliary atresia. In: Bitiary Atresia, edited by R. Ohi, Professional Postgraduate Services, Tokyo, pp. 145 148.

6) Hall, R.J. \& Karrer, F.M. (1990) Biliary atresia: Perspective on transplantation. Pediatr. Surg. Int., 5, 94-99.

7) Heffron, T.G. (1993) Living-related pediatric liver transplantation. Semin. Pediatr. Surg., 2, 248-253. 
8) Houwen, R.H.J., Zwierstra, R.P., Severijnen, R.S.V.M., Rouquet, J., Madern, G., Vos A Bax, N.M., Heymans, H.S. \& Bijleveld, C.M. (1989) Prognosis of extrahepatic biliary atresia. Arch. Dis. Child., 64, 214-218.

9) Karrer, F.M., Lilly, J.R., Stewart, B.A. \& Hall, R.J. (1990) Biliary atresia registry, 1976 to 1989. J. Pediatr. Surg., 25, 1076-1081.

10) Kasai, M. \& Suzuki, S. (1959) A new operation for "non-correctable" biliary atresia: Hepatic portoenterostomy. Shujutsu, 13, 733-739. (in Japanese)

11) Kim, W.K., Park, K.W. \& Lee, S.C. (1987) Recent results of surgical treatment for biliary atresia: Experience at Seoul National University. In: Biliary Atresia, edited by R. Ohi, Professional Postgraduate Services, Tokyo, pp. 137-140.

12) Knisely, A.S. (1990) Biliary atresia and its complications. Ann. Clin. Lab. Sci., 20, $113-118$.

13) Lilly, J.R. (1986) Biliary atresia: The jaundiced infant. In: Pediatric Surgery, edited by K.J. Welch, J.G. Randolph \& M.M. Ravich, Year Book Medical, Chicago, Chap 110, pp. 1047-1056.

14) Mori, K., Nagata, I., Yamagata, S., Sasaki, H., Nishizawa, F., Takada, Y., Moriyasu, F., Tanaka, K., Yamaoka, Y., Kumada, K., Kikuchi, H. \& Ozawa, K. (1992) The introduction of microvascular surgery to hepatic artery reconstruction in living-donor liver transplantation--Its surgical advantages compared with conventional procedures. Transplantation, 54, 263-268.

15) Ohi, R. \& Ibrahim, M. (1992) Biliary atresia. Semin. Pediatr. Surg., 1, 115-124.

16) Otte, J.B., de Ville de Goyet, J., Reding, R., Hausleithner, V., Sokal, E., Chardot, C. \& Debande, B. (1994) Sequential treatment of biliary atresia with Kasai portoenterostomy and liver transplantation: A review. Hepatology, 20, 41S-48S.

17) Otte, J.B., de Ville de Goyet, J., Sokal, E., Alberti, D., Moulin, D., de Hemptinne, B., Veyckemans, F., Van Obbergh, L., Carlier, M., Clapuyt, Ph., Claus, D. \& Jamart, J. (1990) Size reduction of the donor liver is a safe way to alleviate the shortage of size-matched organs in pediatric liver transplantation. Ann. Surg., 211, 146-157.

18) Ryckman, F., Fisher, R., Pedersen, S., Dittrich, V., Heubi, J., Farrell, M., Balistreri, W. \& Ziegler, M. (1993) Improved survival in biliary atresia patients in the present era of liver transplantation. J. Pediatr. Surg., 28, 382-386.

19) Saing, H. \& Tam, P.K.H. (1987) Biliary atresia: The Hong Kong Experience. In: Biliary Atresia, edited by R. Ohi, Professional Postgraduate Services, Tokyo, pp. 141144.

20) Schweizer, P. (1986) Treatment of extrahepatic bile duct atresia: Results and longterm prognosis after hepatic portoenterostomy. Pediatr. Surg. Int., 1, 30-36.

21) Shaw, B.W., Jr., Wood, R.P., Kaufman, S.S., Williams, L., Antonson, D.L., Kelly, D.A. \& Vanderhoof, J.A. (1988) Liver transplantation therapy for children: Part 2. J. Pediatr. Gastroenterol. Nutr., 7, 797-815.

22) Stewart, B.A., Hall, R.J., Karrer, F.M. \& Lilly, J.R. (1990) Long-term survival after Kasai's operation for biliary atresia. Pediatr. Surg. Int., 5, 87-90.

23) Superina, R.A., Strasberg, S.M., Greig, P.D. \& Langer, B. (1990) Early experience with reduced-size liver transplants. J. Pediatr. Surg., 25, 1157-1161.

24) Tan, K.C., Yandza, T., de Hemptinne, B., Clapuyt, Ph., Claus, D. \& Otte, J.B. (1988) Hepatic artery thrombosis in pediatric liver transplantation. J. Pediatr. Surg., 23, 927-930.

25) Tanaka, K., Uemoto, S., Tokunaga, Y., Fujita, S., Sano, K., Nishizawa, T., Sawada, H., Shirahase, I., Kim, H.J., Yamaoka, Y. \& Ozawa, K. (1993) Surgical techniques and innovations in living related liver transplantation. Ann. Surg., 217, 82-91.

26) Tzakis, A.G., Gordon, R.D., Shaw, B.W., Jr., Iwatsuki, S. \& Starzl, T.E. (1985) Clinical presentation of hepatic artery thrombosis after liver transplantation in the cyclosporine era. Transplantation, 40, 667-671.

27) Vacanti, J.P., Shamberger, R.C., Eraklis, A. \& Lillehei, C.W. (1990) The therapy of 
biliary atresia combining the Kasai portoenterostomy with liver transplantation: A single center experience. J. Pediatr. Surg., 25, 149-152. 